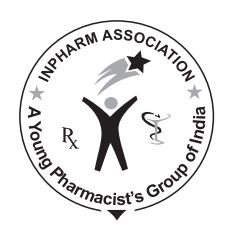

\title{
Pharmacological and Biochemical Interventions of Cigarette Smoke, Alcohol, and Sexual Mating Frequency on Idiopathic Rat Model of Parkinson's Disease
}

\author{
Ambhore NS, Antony S', Mali JK, Kanhed AM, Bhalerao AR², Bhojraj S1 \\ Departments of Pharmacology and Pharmaceutical Chemistry, Konkan Gyanpeeth Rahul Dharkar College \\ of Pharmacy and Research Institute, Karjat, Raigad, 'Departments of Pharmacology, J S S College of \\ Pharmacy, Ooty, Tamilnadu, ${ }^{2}$ Departments of Pharmacology, K M Kundnani College of Pharmacy, Colaba, \\ Mumbai, India
}

Address for correspondence: Prof. Nilesh S. Ambhore; E-mail: nilesh2484@gmail.com

\begin{abstract}
Parkinson's Disease (PD) is a neurodegenerative disorder in the nigrostriatal pathway of animals and humans and is responsible for most of the movement disorders, including rigidity. The present study aimed to determine the effect of chronic cigarette smoke, alcohol intake, and frequent sexual mating on 1-Methyl4-phenyl-1,2,3,6-tertahydro pyridine (MPTP)-induced rat model of PD. After treatment, the effect of these factors was determined by biochemical and molecular evaluation. Dopamine (DA) concentration, antioxidant enzymes, and mitochondrial activity decreased after treatment with cigarette smoke, alcohol, and frequent sexual mating when compared to the values in the control group. Excessive exposure of these factors may lead to neurodegeneration, dopaminergic toxicities, and, ultimately, clinical parkinsonism. Earlier literature from different publisher suggested that nicotine and cigarette smoke can protect the dopaminergic neurons in the substantia nigra against MPTP toxicity. In this study, we assessed the effect of the above three factors on an MPTP-treated rat model and concluded that they have a neurodegenerative effect and were found to be toxic to dopaminergic neurons in the substantia nigra. Further investigation is required to understand the exact etiology of clinical parkinsonism.
\end{abstract}

Key words: Dopamine, mitochondria, MPTP, nigrostriatal pathway

\section{INTRODUCTION}

Parkinson's Disease (PD) has a lifetime risk of $2 \%$,

\begin{tabular}{|c|l|}
\hline \multicolumn{2}{|c|}{ Access this article online } \\
\hline Quick Response Code: & Website: \\
\hline & www.jyoungpharm.in \\
\cline { 2 - 3 } & \\
\hline & Dol: \\
\hline & \\
\hline
\end{tabular}

making it the second most common neurodegenerative disease after Alzheimer's disease. Current demographic trends predict a doubling in the number of cases by 2050. Parkinson's disease is mainly observed due to degeneration of dopaminergic pathway in the brain. ${ }^{[1]}$

However, other neurotransmitter systems (eg, cholinergic, adrenergic, and serotonergic) also degenerate and cell loss is seen in other brain stem nuclei and the cortex. This nondopaminergic degeneration is a major cause of the nonmotor symptoms of PD (eg, cognitive decline, 
autonomic dysfunction). Although sometimes preceding the motor symptoms, these are predominant in the later stages of the disease. ${ }^{[2]}$

Several studies have sought to define the environmental contribution to the etiology of PD. A rural residency and exposure to pesticides appear to increase the risk of the development of PD, particularly of 'young-onset PD'. ${ }^{[3-5]}$ Although an environmental contribution to the cause of PD seems likely, no specific agent has been clearly identified as causative.

There is evidence for a specific defect of $35 \%$ in the activity of mitochondrial complex I in substantia nigra. ${ }^{[6,7]}$ In addition to the mitochondrial defect in PD, there is substantial evidence of free-radical-mediated damage to proteins and lipid in the substantia nigra ${ }^{[8]}$ proteasomal dysfunction, ${ }^{[9]}$ and inflammatory change. ${ }^{[10]}$

Exposure of experimental animals to 1-methyl-4-phenyl1,2,3,6-tetrahydropyridine (MPTP) provides a valuable model of neurotoxicity with behavioral, pathological, and neurochemical features remarkably similar to those of PD. ${ }^{[11]}$

Injection of MPTP causes rapid onset of Parkinsonism. MPTP by itself is not toxic, and as a lipophilic compound can cross the blood-brain barrier. Once inside the brain, MPTP is metabolized into toxic cation 1-Methyl-4Phenylpyridinium $\left(\mathrm{MPP}^{+}\right)$by enzyme L-Monoamine Oxidase (MAO)-B of glial cells. $\mathrm{MPP}^{+}$kills primarily Dopamine (DA)-producing neurons in a part of the brain called the pars compacta of the substantia nigra. $\mathrm{MPP}^{+}$ interferes with complex I of the electron transport chain, a component of mitochondrial metabolism, which leads to cell death and causes the buildup of free radicals and toxic molecules that contribute further to cell destruction. The group of enzymes that form complex I seem to be impaired in PD. ${ }^{[6,12]}$

Because MPTP itself is not directly harmful, the toxic effects of $\mathrm{MPP}^{+}$can be mitigated by the administration of Monoamine Oxidase Inhibitors (MAOIs), such as selegiline. MAOIs prevent the metabolism of MPTP to $\mathrm{MPP}^{+}$by inhibiting the action of MAO-B, minimizing toxicity and preventing neural death. $\mathrm{MPP}^{+}$has quite selective abilities to cause neuronal death in dopaminergic cells; it is presumed to be through a high-affinity uptake process in nerve terminals normally used to reuptake DA after it has been released into the synaptic cleft. The DA transporter moves $\mathrm{MPP}^{+}$inside the cell. ${ }^{[12]}$

\section{MATERIALS AND METHODS}

\section{Animals}

Healthy, adult Wistar rats of both sexes (180-220 gm) were obtained from the Central animal house facility from J S S College of Pharmacy, Ootacamund, Tamil Nadu. The animals were kept in a well ventilated room and were exposed to 12 $\mathrm{hr}$ day and $12 \mathrm{hr}$ night cycle with a temperature of $25 \pm 3^{\circ} \mathrm{C}$; humidity $35-60 \%$. The animals were housed in large, spacious, hygienic polypropylene cages during the experimental period. The animals were fed with water and rat feed ad libitum. All experiments were performed after obtaining prior approval from the Committee for the Purpose of Control and Supervision of Experiments on Animals (CPCSEA) and Institutional Animal Ethics Committee (IAEC).

\section{Chemicals and reagents}

The following chemicals and drug were used: 1-Methyl-4Phenyl-1,2,3,6-Tertahydropyridine (MPTP) (Merck India Ltd, Mumbai), Dopamine (Sd-Fine Chemicals, Mumbai), Glutathione reductase, Ubiquinone, NADH, Reduced Nicotinamide Adenine Dinucleotide Phosphate (NADPH) (Sigma Aldrich, USA), Hexane sulfonic acid, Rotenone Thiobarbituric acid, Sodium dodecyl sulfate, Phenazine methosulfate, Nitro blue tetrazolium (Loba chemicals, Mumbai).

\section{Grouping of animals}

Animals were divided into five groups with 5 male and 5 female rats in each group.

Group I : Control-I (Negative control)

Group II : Sham operated control (Positive Control)

Group III : Cigarette smoke-treated group

Group IV : Alcohol-treated group

Group V : Frequent sexual mating group

\section{Induction of Parkinsonism by MPTP}

On the zero days to each animal intraperitoneal (ip) injections of 1-Methyl-4-phenyl-1,2,3,6- tertahydropyridine (MPTP) $(20 \mathrm{mg} / \mathrm{kg})$ in normal saline were given. MPTP is a neurotoxin, which after absorption is converted to $\mathrm{MPP}^{+}$radical, which specifically degenerates DA-producing neurons in the substantia nigra-a part of the midbrain. ${ }^{[13]}$ Due to degeneration of dopaminergic neurons, the amount of DA production will reduce and lead to Parkinsonism. Subsequently, 48 hours after induction of Parkinsonism, the animals were treated with cigarette smoke, alcohol and frequent sexual mating continuously for 60 days. 


\section{Cigarette smoke treatment}

The exposure system consists of two chambers separated by a perforated wall. In the first chamber (combustion), the cigarette was burned passively and the animals were placed in the second chamber (inhalation). During exposure, the compressed air fed the combustion and directed the smoke flow into the inhalation chamber and then to an exit. ${ }^{[14,15]}$ The animals were subjected to inhalation for $15 \mathrm{~min}$, twice a day with a 12-hour interval. This procedure was done daily up to 60 days.

\section{Alcohol treatment}

Daily about $3.0 \mathrm{~g} / \mathrm{kg}$ body weight of ethanol (alcohol) was ingested orally up to 60 days. Ethanol was administered once a day employing a $20 \%$ solution prepared by mixing $26.9 \mathrm{ml}$ of $95 \%$ ethanol plus $73.1 \mathrm{ml}$ distilled water $(20 \mathrm{~g}$ ethanol in $100 \mathrm{ml}$ water). The effect of ethanol on the contents of DA, in the Central Nervous System (CNS) regions of the rat was examined after 60 days. ${ }^{[16,17]}$

\section{Frequent sexual mating}

Daily mating of the animal with opposite sex up to 60 days by using a harem method (1 male: 3 female) and vice versa. A male was placed in a clear Perspex box $(45 \mathrm{~cm} \times 25 \mathrm{~cm} \times$ $40 \mathrm{~cm}$ ) for $5 \mathrm{~min}$ before a receptive female was introduced; male sexual behaviour was then monitored and recorded for $30 \mathrm{~min}$. If the male failed to display a mount within the first $15 \mathrm{~min}$, the female was removed and replaced with another receptive female and the $30 \mathrm{~min}$ session resumed. ${ }^{[18,19]}$

\section{BIOCHEMICAL EVALUATION}

\section{Estimation of dopamine}

The previously reported HPLC method was followed for DA content analysis. ${ }^{[20]}$ Dissected striata were immediately frozen on dry ice and stored at $-80^{\circ} \mathrm{C}$. Striatal tissues were sonicated in $0.1 \mathrm{M}$ of perchloric acid (about $100 \mu \mathrm{l} / \mathrm{mg}$ tissue). The supernatant fluids were taken for measurements of levels of dopamine by HPLC. Briefly, $20 \mu \mathrm{l}$ of supernatant fluid was isocratically eluted through a $4.6-\mathrm{mm}$ C18 column containing paracetamol $(100 \mathrm{mg} / \mathrm{ml})$ as the internal standard with a mobile phase containing $50 \mathrm{mM}$ ammonium phosphate $\mathrm{pH}$ 4.6, $25 \mathrm{mM}$ hexane sulfonic acid $\mathrm{pH} 4.04$, and $5 \%$ acetonitrile and detected by a UV spectrophotometer detector. The flow rate was $1 \mathrm{ml} / \mathrm{min}$. Concentration of DA was expressed as nanograms per milligram of protein. The protein concentrations of tissue homogenates were measured by Lowry's method.

\section{Estimation of total protein by Lowry's method}

Protein levels were estimated with the Lowry's method, from similar rat brain slices, which were used for DA assay and anti-oxidant enzymes estimations. ${ }^{[21]}$

\section{Lipid peroxidation assay}

Lipid peroxidation in the rat brain homogenate was carried out essentially as described earlier. ${ }^{[22]}$ Rat forebrain (stored at $-80^{\circ} \mathrm{C}$ for less than 8 days) was homogenized in $20 \mathrm{mM}$ Tris-HCl, $\mathrm{pH} 7.4(10 \mathrm{ml})$ at $4^{\circ} \mathrm{C}$ using a Polytron homogenizer. The homogenate was centrifuged at $1000 \times g$ for $10 \mathrm{~min}$ at $4{ }^{\circ} \mathrm{C}$, and the supernatant collected. Further, acetic acid $1.5 \mathrm{ml}(20 \%$; $\mathrm{pH} 3.5), 1.5 \mathrm{ml}$ of thiobarbituric acid $(0.8 \%)$, and $0.2 \mathrm{ml}$ of sodium dodecyl sulfate $(8.1 \%)$ were added to $0.1 \mathrm{ml}$ of the supernatant and heated at $100^{\circ} \mathrm{C}$ for $60 \mathrm{~min}$. The mixture was cooled and $5 \mathrm{ml}$ of n-butanol-pyridine (15:1) mixture, $1 \mathrm{ml}$ of distilled water was added and vortexed vigorously. After centrifugation at $1200 \times g$ for $10 \mathrm{~min}$, the organic layer was separated and absorbance measured at $532 \mathrm{~nm}$ using Elisa plate reader. Malonyldialdehyde (MDA) is an end product of lipid peroxidation, which reacts with thiobarbituric acid to form pink chromogen-thiobarbituric acid reactive substance.

\section{Estimation of catalase}

Catalase (CAT) measurement was done by the ability of CAT to oxidize hydrogen peroxide $\left(\mathrm{H}_{2} \mathrm{O}_{2}\right)$. Potassium phosphate buffer $(2.25 \mathrm{ml})(65 \mathrm{mM}, \mathrm{pH} 7.8)$ and $100 \mu \mathrm{l}$ of the brain homogenate were incubated at $25^{\circ} \mathrm{C}$ for 30 min. An aliquot of $650 \mu \mathrm{l} \mathrm{H}_{2} \mathrm{O}_{2}(7.5 \mathrm{mM})$ was added to the brain homogenate to initiate the reaction. The change in absorption was measured at $240 \mathrm{~nm}$ for 2-3 min and the results were expressed as CAT $\mu \mathrm{mol} / \mathrm{min} \mathrm{mg}$ of protein. ${ }^{[2]}$

\section{Estimation of superoxide dismutase assay}

Superoxide Dismutase (SOD) activity was analyzed by the method described earlier. ${ }^{[23]}$ The assay mixture contained $0.1 \mathrm{ml}$ supernatant, $1.2 \mathrm{ml}$ sodium pyrophosphate buffer ( $\mathrm{pH} 8.3 ; 0.052 \mathrm{M}), 0.1 \mathrm{ml}$ phenazine methosulfate (186 $\mu \mathrm{m}), 0.3 \mathrm{ml}$ nitro blue tetrazolium $(300 \mu \mathrm{M})$, and $0.2 \mathrm{ml}$ $\mathrm{NADH}(750 \mu \mathrm{M})$. The reaction was started by addition of $\mathrm{NADH}$. After incubation at $30^{\circ} \mathrm{C}$ for $90 \mathrm{sec}$, the reaction was stopped by addition of $0.1 \mathrm{ml}$ of glacial acetic acid. The reaction mixture was stirred vigorously with $4.0 \mathrm{ml}$ of $n$-butanol. Colour intensity of the chromogen in butanol was measured spectrophotometrically at $560 \mathrm{~nm}$ and concentration of SOD was expressed as $\mathrm{U} / \mathrm{mg}$ of protein. 


\section{Analysis of glutathione/glutathione reductase}

GSH was measured enzymatically by the method described above. ${ }^{[24]}$ The striata were homogenized in ice-cold perchloric acid $(0.2 \mathrm{M})$ containing $0.01 \%$ EDTA. The homogenate was centrifuged at $10,000 \mathrm{rpm}$ at $4^{\circ} \mathrm{C}$ for $10 \mathrm{~min}$. The enzymatic reaction was started by adding $200 \mu \mathrm{l}$ of clear supernatant in a spectrophotometric cuvette containing $500 \mu \mathrm{l} 0.3 \mathrm{mM} \mathrm{NADPH}, 100 \mu \mathrm{l}$ $6 \mathrm{mM} \mathrm{5,5-dithiobis-2-nitrobenzoic} \mathrm{acid} \mathrm{(DTNB),} \mathrm{and}$ $10 \mu \mathrm{l} 25$ units/ml Glutathione reductase (all the above three reagents were freshly prepared in phosphate buffer at $\mathrm{pH}$ 7.5). The absorbance was measured over a period of $3 \mathrm{~min}$ at $412 \mathrm{~nm}$ at $30^{\circ} \mathrm{C}$. The GSH level was determined by comparing the change of absorbance $(\Delta \mathrm{A})$ of test solution with the $\Delta \mathrm{A}$ of standard GSH.

\section{MOLECULAR PHARMACOLOGY STUDY}

\section{Isolation of mitochondria}

Tissue was homogenized with a Dounce tissue grinder in mitochondrial isolation buffer $(70 \mathrm{mM}$ sucrose, $210 \mathrm{mM}$ mannitol, $5 \mathrm{mM}$ Tris $\mathrm{HCl}, 1 \mathrm{mM}$ EDTA; $\mathrm{pH}$ 7.4) and suspensions were centrifuged at $800 \times g$, at $4^{\circ} \mathrm{C}$, for $10 \mathrm{~min}$. The supernatant fluids were centrifuged at $13000 \times g, 4^{\circ} \mathrm{C}$, for $10 \mathrm{~min}$, and the pellets were washed with mitochondrial isolation buffer and centrifuged at $13,000 \times g, 4^{\circ} \mathrm{C}$, for 10 min to obtain the crude mitochondrial fraction. ${ }^{[25]}$

\section{Complex I activity assay}

NADH: Ubiquinone oxidoreducase (Complex I) activity was measured in the substantia nigra as described in the literature. ${ }^{[25]}$ Brain mitochondria, isolated as above, were lysed by freeze-thawing in a hypotonic buffer $(25 \mathrm{mM}$ $\mathrm{KH}_{2} \mathrm{PO}_{4}, 5 \mathrm{mM} \mathrm{MgCl}_{2} ; \mathrm{pH}$ 7.4). The reaction was initiated by the addition of $50 \mu \mathrm{g}$ mitochondria to the assay buffer hypotonic buffer containing $65 \mu \mathrm{M}$ ubiquinone, $130 \mu \mathrm{M}$ $\mathrm{NADH}, 2 \mu \mathrm{g} / \mathrm{ml}$ antimycin $\mathrm{A}$ and $2.5 \mathrm{mg} / \mathrm{mL}$ defatted bovine serum albumin (BSA)]. The oxidation of $\mathrm{NADH}$ by Complex I was monitored spectrophotometrically at $340 \mathrm{~nm}$ for $2 \mathrm{~min}$ at $30^{\circ} \mathrm{C}$. The activity was monitored for a further $2 \mathrm{~min}$ following the addition of rotenone $(2 \mu \mathrm{g} / \mathrm{ml})$. The difference between the rate of oxidation before and after the addition of rotenone was used to calculate Complex I activity.

\section{Statistical analysis}

Data are expressed as mean \pm SEM of values. The collected data were subjected to appropriate statistical test such as one-way analysis of variance (ANOVA), followed by an appropriate Bonferroni multiple comparisons test. P values of less than 0.01 were considered significant.

\section{RESULTS}

\section{Estimation of dopamines from brain homogenate}

The brain DA level was estimated by using HPLC method. When compared with the control group, Group 2 to 5 showed a significant reduction in the DA levels. When compared with the sham-operated group, Group 3 to 5 showed a significant increase in DA concentration. For the cigarette smoke-treated group, the level of DA was higher than that of alcohol and the frequent sexual mating group [Table 1].

\section{Estimation of protein}

The protein estimation was performed by Lowry's method. When compared with control animals, the concentration of protein was significantly reduced for other treatment groups. But when compared with sham-operated control, it significantly increased the protein concentration for Groups 3, 4, and 5 [Table 2].

\section{In vivo antioxidant parameters}

The level of lipid peroxidation was estimated. When compared with control animals, the level of lipid peroxidation was more for groups 2 to 4 . It was less for group 5 with the significance of $(P<0.01)$. When compared with sham-operated control, the cigarette smoke-treated group showed a higher level of lipid peroxidation, and the alcohol-treated group had the maximum level. For frequent sexual-mating group, the level of lipid peroxidation was less [Table 3].

When compared with control animals, a significant reduction was seen in the level of superoxide dismutase for treatment groups 2 to 5 . When compared with sham-operated control, the superoxide dismutase level significantly reduced for groups 3 and 4 , but at the same time, it increased for group 5 [Table 3].

The control group showed a significant reduction in the glutathione concentration when compared with groups 2 to 5 . When compared with sham-operated control, the level of glutathione reductase was significantly increased for groups 2 to 3 [Table 3].

For catalase activity, the control group showed less 
Ambhore, et al:: Evaluation of cigarette smoke, alcohol and sexual mating frequency on idiopathic rat model of PD

Table 1: Effect of cigarette smoke, alcohol, and frequent sexual mating on concentrations of dopamine in the brain homogenate of treatment groups

\begin{tabular}{|c|c|}
\hline Treatment Group & $\begin{array}{l}\text { Dopamine concentration } \\
\text { (ng/mg of protein) }\end{array}$ \\
\hline Control group & $1754.287 \pm 5.432$ \\
\hline Sham-operated control & $248.78 \pm 2.322^{* * *}$ \\
\hline $\begin{array}{l}\text { Cigarette smoke-treated } \\
\text { group }\end{array}$ & $386.927 \pm 2.124 * * * \ldots \#$ \\
\hline Alcohol-treated group & $156.164 \pm 1.470^{* * *} \ldots$ \\
\hline Frequent sexual-mating group & $178.387 \pm 2.249^{* * *}$ \\
\hline
\end{tabular}

Table 2: Effect of cigarette smoke, alcohol, and frequent sexual mating on total protein concentrations in the brain homogenate of treatment groups by using Lowry's method

Treatment Group

Concentration of protein (mg/100 mg of tissue)

Control group $30.24 \pm 0.2049$

Sham-operated control

Cigarette smoke-treated group

Alcohol-treated group

Frequent sexual-mating group

$6.905 \pm 0.2041^{* * *}$

$8.695 \pm 0.0523 * * * \ldots$ $9.94 \pm 0.08131 * * * \ldots$ $20.57 \pm 0.0878 * * * \ldots$

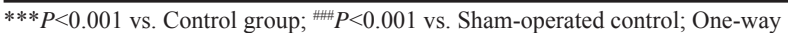
ANOVA followed by Bonferroni multiple comparisons test.

Table 3: Effect of cigarette smoke, alcohol, and frequent sexual mating, on in vivo antioxidant parameters of the brain homogenate of treatment groups

\begin{tabular}{|c|c|c|c|c|}
\hline Treatment Group & $\begin{array}{l}\text { Lipid peroxidation } \\
\text { (nmol/mg protein) }\end{array}$ & $\begin{array}{c}\text { Superoxide dismutase } \\
(\mathrm{U} / \mathrm{ml})\end{array}$ & $\begin{array}{l}\text { Glutathione reductase } \\
\text { (nmol/mg of protein) }\end{array}$ & $\begin{array}{c}\text { Catalase }(\mu \mathrm{mol} / \mathrm{min} \\
\text { mg protein) }\end{array}$ \\
\hline Control group & $13.180 \pm 0.1452$ & $103.71 \pm 1.281$ & $1.020 \pm 0.005$ & $0.969 \pm 0.071$ \\
\hline Sham-operated control & $46.957 \pm 1.117 * * *$ & $65.521 \pm 0.4867 * * *$ & $0.593 \pm 0.019 * * *$ & $0.482 \pm 0.021 * * *$ \\
\hline Cigarette smoke-treated group & $44.130 \pm 0.6254 * * *, \mathrm{~ns}$ & $43.984 \pm 0.726^{* * *}$ & $0.767 \pm 0.005 * * *$ & $0.581 \pm 0.03 * * *, \mathrm{~ns}$ \\
\hline Alcohol-treated group & $71.613 \pm 1.953 * * * \ldots$ & $48.894 \pm 0.620 * * * \ldots \#$ & $0.731 \pm 0.009 * * * \#$ & $0.559 \pm 0.014 * * *, \mathrm{~ns}$ \\
\hline Frequent sexual-mating group & $18.804 \pm 0.2957 * * \ldots$ & $74.475 \pm 0.491 * * * \ldots \#$ & $0.806 \pm 0.002 * * * \#$ & $0.721 \pm 0.03 * * * \#$ \\
\hline
\end{tabular}

***P<0.001, $* * P<0.01$ vs. Control group; ${ }^{\# \#+} P<0.001,{ }^{\#} P<0.01$, ns $P>0.05$ vs. Sham-operated control; One-way ANOVA followed by Bonferroni multiple comparisons test.

Table 4: Effect of cigarette smoke, alcohol, and frequent sexual mating on mitochondrial Complex I activity in the brain homogenate of treatment groups

Treatment Group Complex I activity $(\mathrm{nm} / \mathbf{m i n} / \mathbf{m g}$ protein)

Control group $99.292 \pm 1.903$

Sham-operated control

Cigarette smoke-treated group

Alcohol-treated group

Frequent sexual-mating group $46.012 \pm 4.073 * * *$ $42.947 \pm 1.537 * * * \mathrm{~ns}$ $45.571 \pm 1.626^{* * *}$ ns $74.025 \pm 1.271 * * * \ldots$

*** $P<0.001$ vs. Control group; ${ }^{\# \#} P<0.001,{ }^{\text {ns }} P>0.05$ vs. Sham-operated control; One-way ANOVA followed by Bonferroni multiple comparisons test.

concentration when compared with treatment groups 2 to 5. But when compared with sham-operated control, the catalase activity was significantly increased for frequent sexual-mating groups. Groups 3 and 4 did not show significant variation in the catalase activity [Table 3].

\section{Molecular estimation}

The complex I activity was measured from the mitochondrial fraction of brain homogenate. When compared with the control group, it showed a significant reduction in the mitochondrial complex I activity for groups 2 to 5 . When compared with sham-operated control, the complex I activity was significantly increased for frequent sexualmating group and without any significant alteration for groups 3 and 4 [Table 4].

\section{DISCUSSION}

Various studies were conducted to access and evaluate the influence of cigarette smoke, alcohol intake and active sex and their relationship with Parkinsonism, or dopaminergic activities in the brain.

The DA concentration in the midbrain region showed a less level for sham operated control group, obviously it was higher in cigarette smoke treated group and low for frequent sex and alcohol-treated groups. It was previously reported that alcohol administration and sexual stimulation leads to release of DA and increase in the metabolism of dopamine to Dihydroxy Phenyl Acetic Acid (DOPAC) and Homovanillic Mandelic Acid (HVA), respectively. ${ }^{[2]}$ The increase in DOPAC and HVA in the repeated sexual satiety period could reflect the enhanced dopaminergic transmission.

Furthermore, it was evident from earlier studies that the neurochemical changes found during the intervening state of sexual inactivity (ie, increased levels of DA metabolites) are reminiscent of the effects of DA receptor blockers; this suggests a possible neurochemical mechanism for sexual refractoriness. It was also seen that as the DA level increased, sexual mating frequency in animals increased subsequently. ${ }^{[27]}$ In the case of alcohol treatment, it was proved that the conversion level of DOPAC and HVA was elevated according to the concentration of alcohol in the blood. ${ }^{[28]}$ And it was earlier reported that ethanol had no effect on endogenous release of DOPAC, HVA, or DA. However, ethanol did enhance the potassium stimulation, calcium-dependent release of glutamate and aspartate from the striatal region when compared with the normal brain. 
These excitatory mediators followed by DA release could have led to neurotoxicity and further neuronal damage of dopaminergic neurons. But in our studies, we could analyze the level of ultimate concentration of DA after 60 days by HPLC method. This states that either cigarette smoke, alcohol, or frequent sexual mating could reduce the DA concentration, and this may be due to an exhaust mechanisms followed by chronic discharge and catabolism of DA up to 60 days, followed by MPTP treatment.

The estimation of total protein concentration was carried out to assess two factors-one was to know the extent of protein degradation or catabolism that has taken place in the brain and the other is for estimation of DA present in the brain homogenates. The level of protein concentration in cigarette smoke and alcohol-treated groups was drastically reduced compared to that in the frequent sexual-mating group. These results suggest that higher cigarette smoke or alcohol intake could induce the relative catabolism of protein or hastens its denaturation.

Oxidative stress and oxidative damage to critical biomolecule is an important process mediating cell death in PD. However, it has not yet been proven that this is the primary event to initiate nigral cell degeneration. ${ }^{[29]}$ The studies showed an increase in lipid peroxidation for cigarette smoke and alcohol-treated groups, but not for frequent sexual-mating group and the activities of Glutathione reductase, superoxide dismutase, and catalase were reduced by cigarette smoke, alcohol, and frequent sexual-mating groups. Reduction in glutathione might impair $\mathrm{H}_{2} \mathrm{O}_{2}$ clearance, promote formation of $\mathrm{OH}$ radical, and produce oxidative stress. All the antioxidant defence mechanisms were related and a disturbance on one might damage the balance in all. The depletion in Glutathione reductase content and enhancement of lipid peroxidation leads to degeneration of nigrostriatal neurons and, consequently, leads to a reduction in the content of catecholamine.

Earlier studies have proven that MPTP inactivates oxygensensitive mitochondrial aconitase in the substantia nigra; further, MPTP mobilises a novel early pool of chelatable mitochondrial ions that balance mitochondrial aconitase inactivation and presides over neurotoxicity. Finally, MPTP-induced mitochondrial aconitase inactivation, chelatable ion, and neurotoxicity lead to degeneration of dopaminergic neurons. Mitochondrial dysfunction and bio-energetic declaim are directly related with a reduction in the complex I activities. ${ }^{[30]}$ Our studies demonstrate that the complex I activity was significantly reduced for the cigarette smoke and alcohol-treated groups as compared to that of the frequent sexual-mating group. It has been assumed that the dopaminergic cells in the substantia nigra are lost through a cell necrosis and even possibly precipitated by oxidative damage or complex I deficiency, which might have happened because of cigarette smoke and alcohol and less with frequent sexual mating.

In conclusion, we have demonstrated that cigarette smoke, alcohol intake, and frequent sexual mating all proved to have a neurodegenerative effect and were found to be toxic to dopaminergic neurons in the substantia nigra. This suggests that these three factors may lead to clinical parkinsonism through all or any of the diseased parameters. Thus, there is still a need for detailed and specific pharmacological or biochemical or molecular level of discourse to understand the exact etiology or causative factors of clinical parkinsonism to resolve the mystery of neurodegenerative diseases.

\section{REFERENCES}

1. Schapira AH. Neurobiology and treatment of Parkinson's disease. Trends Pharmacol Sci 2009;30:41-7.

2. Chaudhuri KR, Healy DG, Schapira AH. Non-motor symptoms of Parkinson's disease: Diagnosis and management. Lancet Neurol 2006;5:235-45.

3. Rajput AH, Rozdilsky B. Early onset Parkinson's disease in Saskatchewanenvironmental considerations for etiology. Can J Neurol Sci 1991;13:312-6.

4. Schapira AH. Etiology of Parkinson's disease. Neurology 2006;66:S10-23.

5. Semchuk KM, Love EJ, Lee RG. Parkinson's disease and exposure to agricultural work and pesticide chemicals. Neurology 1992;42:1328-35.

6. Schapira AH, Cooper JM, Dexter D, Clark IB, Jenner P, Marsden CD. Mitochondrial complex I deficiency in Parkinson's disease. J Neurochem 1990;54:823-7.

7. Mann VM, Cooper JM, Daniel SE, Srai K, Jenner P, Marsden CD, et al. Complex I, iron, and ferritin in Parkinson's disease substantia nigra. Ann Neurol 1994;36:876-81.

8. Owen AD, Schapira AH, Jenner P, Marsden CD. Oxidative stress and Parkinson's disease. Ann N Y Acad Sci 1996;786:217-23.

9. Olanow CW, McNaught KS. Ubiquitin-proteasome system and Parkinson's disease. Mov Disord 2006;21:1806-23.

10. Hartmann AS, Hunot S, Hirsch EC. Inflammation and dopaminergic neuronal loss in Parkinson's disease: A complex matter. Exp Neurol 2003;184:561-4.

11. Royland JE, Langston JW. MPTP a dopaminergic neurotoxin. In: Kosrezewa RM, editor. Highly Selective Neurotoxins: Basic and Clinical Applications. NJ: Humana Press; 1998. p. 141-94.

12. Langston JW. The Impact of MPTP on Parkinson's Disease Research: Past, Present, and Future. In: Factor SA, Weiner WJ, editors. Parkinson's Disease. Diagnosis and Clinical Management. Demos Medical Publishing; 2002. p. 210-50.

13. Fujikawa T, Miguchi S, Kanada N, Nakai N, Ogata M, Suzuki I, et al. Acanthopanax senticosus Harms as a prophylactic for MPTP induced Parkinson's disease. J Ethnopharmacol 2005;97:375-81.

14. Riveles K, Huang LZ, Quik M. Cigarette smoke, nicotine and cotinine protect against 6-hydroxydopamine-induced toxicity in SH-SY5Y cells. Neurotoxicology 2008;820:1-7.

15. Mello PR, Okay TS, Botelho C. The effect of exposing rats to cigarette smoke on milk production and growth of offspring. J Pediatr 2007;83:267-73.

16. Heil SH, Hungund BI, Zheng ZH, Jen KC, Subramanian MG. Ethanol and lactation: Effect on milk lipid s and serum constituents. Alcohol 1998;18:43-8. 
$\mathrm{m}$ hore, et al:: Evaluation of cigarette smoke, alcohol and sexual mating frequency on idiopathic rat model of PD

17. Jerlhag E. The antipsychotic aripiprazole antagonizes the ethanol and amphetamine induced locomotor stimulation in mice. Alcohol 2008;42:123-7.

18. Govic A, Levay EA, Hazi A, Penman J, Kent S, Paolini AG. Alteration in male sexual behaviour, attractiveness and testosterone levels induced by an adultonset calorie restriction regimen. behavioural. Brain Res 2008;190:140-6.

19. Chauhan NS, Rao CV, Dixit VK. Effect of Curculigo orchioides Rhizomes on sexual behaviour of male rats. Fitoterapia 2007;78:530-4.

20. Cleren C, Calingasan NY, Chen J, Beal MF. Celestrol protects against MPTP and 3-nitropropionic acid induced neurotoxicity. J Neurochem 2005;94:995-1004.

21. Sadasivam S, Manickam A. Biochemical Methods. $2^{\text {nd }}$ ed. New Delhi: New Age International Pvt. Limited Publication; 2004. p. 57-8.

22. Mukherjee PK, Nazeer Ahamed KF, Kumar V, Mukherjee K, Houghton PJ. Protective effect of biflavones from Araucaria bidwillii hook in rat cerebral ischemia/reperfusion induced oxidative stress. Behav Brain Res 2007;178:221-8.

23. Raja S, Nazeer Ahamed KF, Kumar V, Mukherjee K, Bandyopadhyay A, Mukherjee PK. Antioxidant effect of Cytisus scoparius against carbon tetrachloride treated liver injury in rats. J Ethnopharmacol 2007;109:41-7.

24. Tariq M, Khan HA, Moutaery KA, Deeb SA. Protective effect of quinqcrine on striatal dopamine levels in 6-OHDA and MPTP model of Parkinsonism. Brain Res Bull 2001;54:77-82.
25. Liang LP, Patel M. Iron sulfur enzyme mediated mitochondrial superoxide toxicity in experimental Parkinson's disease. J Neurochem 2004;90:1076-84.

26. Cruz-Casallas PE, Nasello AG, Hucke EE, Felicio LF. Dual modulation of male sexual behaviour in rats by central prolactin: Relationship with in vivo striatal dopaminergic activity. Psychoneuroendocrinology 1999;24:681-93.

27. Mas M, Fumero B, Fernandez-Vera JR, Gonzalez-Mora JL. Neurochemical correlates of sexual exhaustion and recovery as assessed by in vivo microdialysis. Brain Res 1995;675:13-9.

28. Murphy JM, Cunningham SD, McBride WJ. Effect of $250 \mathrm{mg} \%$ ethanol on monoamine and amino acid release from rat striatal slice. Brain Res Bull 1985;14:439-42.

29. Bishnoi M, Chopra K, Kulkarni SK. Co-administration of nitric oxide (NO) donors prevents haloperidol-induced orofacial dyskinesis, oxidative damage and change in striatal dopamine levels. Pharmacol Biochem Behav 2009;91:423-9.

30. Perry JC, Cunha CD, Franci JA, Andreatini R, Miyoshi E, Tufik S Behavioural and neurochemical effect of phosphatidylserine in MPTP lesion of the substantia nigra of Rats. Eur J Pharmacol 2004;484:225-33.

How to cite this article: Ambhore NS, Antony S, Mali JK, Kanhed AM, Bhalerao AR, Bhojraj S. Pharmacological and biochemical interventions of cigarette smoke, alcohol, and sexual mating frequency on idiopathic rat model of Parkinson's disease. J Young Pharmacists 2012;4:177-83.

Source of Support: Nil, Conflict of Interest: None declared.

\section{Staying in touch with the journal}

1) Table of Contents (TOC) email alert Receive an email alert containing the TOC when a new complete issue of the journal is made available online. To register for TOC alerts go to www.jyoungpharm.in/signup.asp.

\section{2) RSS feeds}

Really Simple Syndication (RSS) helps you to get alerts on new publication right on your desktop without going to the journal's website. You need a software (e.g. RSSReader, Feed Demon, FeedReader, My Yahoo!, NewsGator and NewzCrawler) to get advantage of this tool. RSS feeds can also be read through FireFox or Microsoft Outlook 2007. Once any of these small (and mostly free) software is installed, add www.jyoungpharm.in/rssfeed.asp as one of the feeds. 